\title{
The Impacts of Brexit on European Equity Markets
}

\author{
Mária Bohdalová1, Michal Greguš² \\ Comenius University \\ Faculty of Management, Department of Information Systems \\ Odbojárov 10, 82005 Bratislava, Slovakia \\ ${ }^{1}$ E-mail: maria.bohdalova@fm.uniba.sk \\ ${ }^{2}$ E-mail: michal.gregus@fm.uniba.sk
}

\begin{abstract}
The aim of this paper is to give a comprehensive description of the risk dependence and interdependence between selected European stock markets and Brexit equity in the period spanning from January, 7, 2000 to February, 3, 2017. We have studied behavior of extreme quantiles using quantile regression approach. This approach is robust because it is based on the use of various measures of central tendency and dispersion statistics for a detailed analysis of the relationship between variables. We have found evidence of significant interdependence /independence between financial markets and Brexit uncertainty. The analysis of upper and lower quantiles allows us to observe that the interdependence is positive asymmetric and higher for bear markets compared to bull or normal market conditions in the period before the Brexit vote. Moreover, we have analyzed the influence of the Brexit vote on selected markets. We have found that one or two or three days after voting the dependence structure was changed mainly in normal market conditions for French and Turkish markets, while Polish and Spanish markets were not significantly influenced.
\end{abstract}

Keywords: Brexit, quantile regression, risk, stock market

JEL codes: $G 15, G 17$

\section{Introduction}

The United Kingdom with its high-performing economy has helped the European Union reach the top in the ranks of the world's most powerful economies. The departure of the UK from the EU can significantly affect the European Community in the future. June 23, 2016 referendum to leave the European Union (EU) known as the vote on Brexit ("British exit") renewed an interest in European integration. Despite the fact that the concerns related to the future of the Common European Union have never completely stopped, Brexit caused an unprecedented challenge and questioned the homogeneity of the European countries on which the success of the monetary union is based. The vote's result shook global markets, causing the British pound to fall to its lowest level against the dollar in 30 years. There is inconsistency of opinion about the influence of this vote on financial markets.

In this paper, we have analyzed the impact of Brexit on selected European markets using economic policy uncertainty index for Europe, the United Kingdom and index called EPUCBREX for Brexit. The daily data have been obtained from data provider Bloomberg L.P. The construction of this index is based on newspaper articles 
regarding policy uncertainty about economy, uncertainty and information about spending, deficit, regulation, budget, tax, policy, or the Bank of England, or ECB (Baker et al., 2015). We have taken EPUCBREX index as a risk factor for analyzing six European markets - the DAX - German market, CAC40 - French market, WIG20 - Polish market, ISEQ - Irish stock market, IBEX - Spanish stock market and XU100 - Turkish stock market. We have used linear quantile regression approach to obtain the conditional dependence structure for specific quantiles. Slope $\beta(q)$ of the quantile regression line estimates the influence of Brexit on the $q$-th quantiles of the stock market index.

The aim of this paper is to find the linkage between the selected stock markets and the uncertainty caused by Brexit. Is there an asymmetric dependence or a symmetric one? Which market has been influenced the most by Brexit? Which market has remained stable? The paper gives answers to these questions based on an empirical study. The data used in our empirical study are daily data for the period from January, 7, 2000 to February, 3, 2017; all data are expressed in EUR. Our findings can give implications to portfolio risk managers, policymakers, international investors in terms of risk management which should vary per change in economy.

The remainder of the paper is organized as follows: Next section briefly reviews the literature, the following section describes the quantile regression methodology and data used. Our empirical analysis with results are then provided. Conclusions and the discussion are presented in the last section.

\section{Literature Review}

The opinions about the influence of the vote on financial markets are inconsistent. Some authors (Ringe, 2017) argue that, in reality, the impact of Brexit on financial services will be minuscule, if not irrelevant. Raddant (2016) analyzed response of selected European stock markets to Brexit. He analyzed the correlation of market indices, stock volatility and the special role of stocks from the financial sector.

Schiereck et al. (2016) investigated the stock and CDS market reactions on Brexit and compared them with the Lehman Brothers bankruptcy. For EU banks, they found that the short-run drop in stock prices was more pronounced than Lehman's bankruptcy, and they observed a large increase in their CDS spreads. For non-EU banks, they found neither significant stock reactions nor CDS price reactions.

Analysis of investor's reactions to Brexit on the Warsaw Stock Exchange market has been investigated in Jackowicz et al. (2017). The authors found mostly uniform reactions of the investors using OLS regressions with robust standard errors and industry sector dummies. Sita (2017) investigated sensitivity of the stock volatility to the market and exchange rate volatility one day after the Brexit vote with $\mathrm{U}$ shape pattern result.

Plakandaras et al. (2017) argued that depreciation of the FX rate GBP to USD is related to the uncertainty caused by Brexit while uncertainty is quantified according 
to an index based on news related to economic uncertainty EPU. They used linear, nonlinear and machine learning models to predict the exchange rate and its realized volatility in pre- and post-Brexit period.

Modeling the dependence of financial market developments on current political and economic conditions or on financial crises is an issue often studied in the literature. This relationship can be described mainly by the Pearson correlation coefficient, or by OLS method with the intention to explore average co-movement (Alexander, 2008). Embrechts et al. (2002) showed that the concept of the linear correlation leads to misinterpretation when conditions of elliptical multivariate distribution are not fulfilled. Bae et al. (2003) showed that correlations give equal weight to small and large returns; therefore, they are not appropriate for an evaluation of the differential impact of large returns. Embrechts et al. (2003) introduced copula framework for modeling the dependence of the financial variables. Hu (2006) proposed using mixed copula for measuring across-market dependence and introduced the term degree and structure of dependence in copula framework. Baur (2013) isolated both components of dependence (degree and structure of dependence) from the quantile regression approach and he showed that financial crises or economic distress cause changes in dependence of the financial markets onto non-linear or asymmetric relation. Quantile regression has been used in many papers concerning the risk and dependence analysis (Alexander, 2008, Baur, 2013, Mensi et al. 2014, Aymen, Mongi, 2016), etc.

\section{Methodology and Data}

Quantile regression was developed by Koenker and Bassett in 1978 (Koenker, Bassett, 1978) as an extension of the traditional least squares estimation of the conditional mean. Quantile regression is a distribution-free technique to estimate the effect of a regressor on the quantiles of the response distribution. Let $Y$ be a linearly dependent variable on variable $X$. The quantile regression expresses the conditional quantiles of dependent variable $Y$ for given independent variable $X$, based on an arbitrary joint distribution. It is assumed that the errors of the quantile regression are i.i.d with the specific error distribution function $F_{\varepsilon}$. We take the $q$-th conditional quantile function $Q_{y}(q \mid X)$ of $Y$ specified by regression model (Mensi et al. 2014)

$Q_{y}(q \mid X)=\inf \left\{b \mid F_{y}(b \mid X) \geq q\right\}=\sum_{k} \beta_{k}(q) X_{k}$,

where $F_{y}(b \mid X)$ is a conditional distribution function of $Y$ for given $X$. Quantile regression coefficient $\beta_{k}(q)$ determines the dependence between random variable $X$ and the $q$-th conditional quantile of $Y$. The values of $\beta_{k}(q)$ for $q \in[0,1]$ determine the whole dependence structure of $Y$. The dependence of $Y$ based on an explanatory variable in vector $X$ could be either constant where the values of $\beta_{k}(q)$ do not change for different values of $q$ or monotonically increasing (decreasing) when 
$\beta_{k}(q)$ increases (decreases) with the value of $q$ or symmetric (asymmetric) where the value of $\beta_{k}(q)$ is similar (dissimilar) for low and high quantiles (Aymen and Mongi, 2016). The coefficients of $\beta_{k}(q)$ for a given $q$ are estimated by minimizing the weighted absolute deviations between $Y$ and $X$

$\hat{\beta}(q)=\min _{\alpha, \beta} \sum_{t=1}^{T}\left(q-1_{Y_{t} \leq \alpha+\beta X_{t}}\right)\left|Y_{t}-\left(\alpha+\beta X_{t}\right)\right|$,

where

$1_{Y_{t} \leq \alpha+\beta X_{t}}=\left\{\begin{array}{lcc}1 & \text { if } & Y_{t} \leq \alpha+\beta X_{t} \\ 0 & \text { otherwise }\end{array}\right.$.

\subsection{Model Specification}

We provide two models to analyse the linkage between Brexit and the selected European markets. In order to investigate the effect of the uncertainty about Brexit we have used the quantile regression model that explains the relationship between the stock market $Y$ (developed or emerging market) and Brexit uncertainty as an independent variable. This dependency can be expressed by equation

$Q_{Y}(q \mid X)=\alpha(q)+\beta(q) E P U C B R E X+\varepsilon$.

In order to analyze the effect of the Brexit vote on June 23, 2016 we include dummy variable $\mathrm{D}_{k \text {-day }}$ into model (4). $\mathrm{D}_{k \text {-day }}$ is the Brexit vote effect dummy variable that takes the value equal to one in the period starting from $k$-th day after voting, where $k=1,2,3$ and zero otherwise. Parameters $\gamma(q)$ and $\theta(q)$ capture the additional marginal effects of the conditional variable in the sub period after Brexit vote for each quantile $q$ in comparison with the effects measured by parameters $\alpha(q)$ and $\beta(q)$ before the voting subperiod.

$$
Q_{Y}(q \mid X)=\alpha(q)+\beta(q) E P U C B R E X+\mathrm{D}_{k-d a y}[\gamma(q)+\theta(q) E P U C B R E X]+\varepsilon .
$$

Equation (5) enables us to examine the vote effect on the dependence structure and the co-movement between the selected European stock markets and the Brexit vote.

\subsection{Data}

In this paper, we have shown the effect of Brexit uncertainty and Brexit vote on selected developed and emerging European markets. Developed European markets are represented by German DAX index, French CAC40, Irish ISEQ and Spanish IBEX stock market index. Emerging European stock markets are represented by Polish WIG20 and Turkish XU100 stock market indices. The choice of the markets has been based on the fact that Germany is the strongest member of the EU and France is the second strongest pillar of the European Union, where the development during the recent period just before the election was quite uncertain and therefore interesting to analyze. We have chosen Turkey and Poland because these countries 
are comparable in size to Germany or France, and Ireland and Spain were chosen as the countries that could be in our opinion influenced the most by Brexit.

The daily data were collected from January, 72000 to February, 3, 2017. Data provider is Bloomberg L.P. All data are expressed in EUR. The closing prices of analyzed time series are nonstationary, therefore we have used logarithmic returns ( $\log$ returns are obtained by formula: $r_{t}=\ln P_{t} / \ln P_{t-1}, t=1 \ldots, T$, where $P_{t}$ is the closing price at time $t$ excluding account dividends).

\section{Results and Discussion}

Table 1 provides the results obtained using IBM SPSS software. We have estimated quantile regressions with intercept for next nine quantiles $q=\{0.01,0.05,0.1$, $0.25,0.5,0.75,0.90,0.95,0.99\}$. The table shows the quantile regression estimates for each market index return per the empirical model defined by equation (4). $t$-statistic from interval $(-1.96,1.96)$ denotes statistical significance at $5 \%$ level.

We have found a significant positive effect of Brexit uncertainty on each stock market. The strongest and symmetric dependence of the DAX log returns on Brexit is in $5 \%$ and $95 \%$ quantile, then for $25 \%$ and $99 \%$ quantile the dependence is slightly lower and finally for $50 \%$ and $90 \%$ quantiles. The lowest significant dependence was for the $1 \%$ quantile. The effect of Brexit uncertainty on French market is slightly higher as compared to German market. The effect is positive and significant for all quantiles. We see the strongest and the same effect for $5 \%$ and $10 \%$ quantile. For other quantiles, the influence of Brexit uncertainty is lower in $25 \%$ and $1 \%$ quantile. From the median to $90 \%$ quantile, the effect is stable. Brexit uncertainty has the lowest impact in $99 \%$ quantile.

The dependency of the Polish market on Brexit uncertainty is oscillating, positive and significant. We can find a symmetric influence in several quantiles. The highest impact of Brexit uncertainty has appeared in the 5\% and $95 \%$ quantile, and then in the $90 \%$ and $99 \%$ quantile. Comparable effect can be observed also in lower and upper quartiles. Then the median follows and the lowest influence is in bear markets in the $1 \%$ quantile.

Brexit uncertainty had the strongest influence on the Irish market, mainly in bear markets. The influence has been positive gradually decreasing from $1 \%$ to $90 \%$ quantile. In bull markets (in $95 \%$ and $99 \%$ ), the influence of Brexit uncertainty has again increased, but it has been lower compared to bear markets.

The Spanish stock market has been relatively affected the most positively by Brexit uncertainty. The dependence has been the highest for the $1 \%$ quantile, gradually declining and moderately stabilized over the median.

The Turkish market has been slightly oscillating influenced by Brexit uncertainty, with the highest positive impact for the $5 \%$ quantile. Brexit uncertainty had the lowest impact in bull markets ( $99 \%$ quantile) (see Table 1 ). 
Table 1 Quantile regression estimates of the coefficients

\begin{tabular}{|c|c|c|c|c|c|c|c|c|c|c|}
\hline & & .010 & .050 & 0.100 & 0.250 & 0.500 & 0.750 & 0.900 & 0.950 & 0.990 \\
\hline \multirow{4}{*}{ D } & (q) & .03 & 01 & 1 & 0 & 0 & .00 & 01 & 01 & .03 \\
\hline & 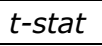 & זע. & 4.87 & 5.17 & .00 & 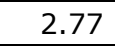 & .66 & .69 & .40 & 5.37 \\
\hline & $\beta(q)$ & .87 & 94 & 91 & 2 & 91 & 90 & 91 & 4 & .92 \\
\hline & stat & 17.06 & 3.76 & 40.63 & 77.16 & 88.83 & 78.88 & 8.43 & 4.95 & 12.18 \\
\hline \multirow{4}{*}{$\mathrm{AC}$} & 9) & 2 & 01 & -0.01 & 00 & 00 & .00 & 01 & 01 & .02 \\
\hline & $t$-stat & -29.06 & -32.52 & -42.34 & -32.18 & 0.92 & 35.25 & 42.97 & 40.87 & 28.92 \\
\hline & $\beta(q)$ & 95 & 0.98 & 0.98 & 0.96 & 0.93 & 0.93 & 0.93 & 0.92 & 0.89 \\
\hline & $t$-stat & 16.40 & 32.68 & 61.08 & 94.10 & 06.76 & 99.21 & 58.08 & 39.88 & 14.49 \\
\hline \multirow{4}{*}{ IG } & $\alpha(q)$ & -0.04 & -0.02 & -0.02 & -0.01 & 0.00 & 0.01 & 0.02 & .02 & 0.04 \\
\hline & $t$-stat & 24.14 & 34.93 & -39.30 & -29.96 & 0.85 & 31.46 & 44.72 & 34.32 & 24.79 \\
\hline & $\beta(q)$ & 0.66 & 0.79 & 0.73 & 0.72 & 0.68 & 0.72 & 0.78 & .79 & 0.78 \\
\hline & $t$-stat & 4.96 & 14.96 & 21.58 & 35.11 & 36.02 & 34.45 & 25.93 & 14.99 & 6.14 \\
\hline \multirow{4}{*}{ ISEQ } & $\alpha(q)$ & -0.03 & -0.02 & -0.01 & 0.00 & 0.00 & 0.01 & 0.01 & .02 & 0.03 \\
\hline & $t$-stat & 7.01 & 5.64 & -30.23 & -30.34 & .64 & 34.59 & 43.61 & 35.16 & 24.97 \\
\hline & $\beta(q)$ & 0.77 & 0.77 & 0.75 & 0.69 & .67 & 0.65 & 0.65 & .68 & 0.76 \\
\hline & $t$-stat & 78 & 21.42 & 27.17 & 55.62 & 50.65 & 54.14 & 34.14 & 20.48 & 9.13 \\
\hline \multirow{4}{*}{ IBE } & $\alpha(q)$ & -0.03 & -0.02 & -0.01 & -0.01 & 0.00 & 0.01 & 0.01 & 0.02 & 0.03 \\
\hline & $t$-stat & 7.24 & 31.28 & -47.33 & -29.47 & 4 & 33.74 & 36.79 & 42 & 24.97 \\
\hline & $\beta(q)$ & 0.99 & 87 & 0.87 & 0.84 & .82 & 0.83 & .83 & 83 & 0.82 \\
\hline & $t$-stat & 12.38 & 24 & 47.57 & 63.26 & .81 & 68.30 & 36.77 & 25.16 & 10.13 \\
\hline \multirow{4}{*}{0100} & $\alpha(q)$ & -0.07 & 4 & -0.03 & -0.01 & 00 & 01 & .02 & 04 & 0.07 \\
\hline & t-stat & 2.09 & -42.49 & -46.74 & -28.40 & 1.27 & 29.67 & 43.12 & 32.85 & 24.48 \\
\hline & $\beta(q)$ & 0.79 & 0.83 & 0.82 & 0.77 & 0.74 & 0.82 & 0.80 & 0.73 & 0.64 \\
\hline & -stat & 3.17 & 2.16 & 8.99 & 25.93 & 0.03 & 26.54 & 18.39 & 8.80 & 3.04 \\
\hline
\end{tabular}

Source: Author's calculations based on data from Bloomberg

Quantile regression estimates of the regression parameters are shown in Figure 1Figure 3 in accordance with Eq. (4). Note that the dashed line shows the quantile regression estimates of the regression parameters across the quantile ranging from 0.01 to 0.99 . Gray band depicts $95 \%$ confidence intervals for the quantile regression parameter estimates.

Figure 4 compares the impact of Brexit uncertainty on individual markets. We see that in bear markets, Brexit had the greatest impact on the Spanish stock market, followed by the French and German markets, followed by the Turkish, Irish stock market. Brexit had the smallest impact on the Polish stock market. 
Figure 1 Quantile regression estimates of the regression parameters for DAX, CAC40
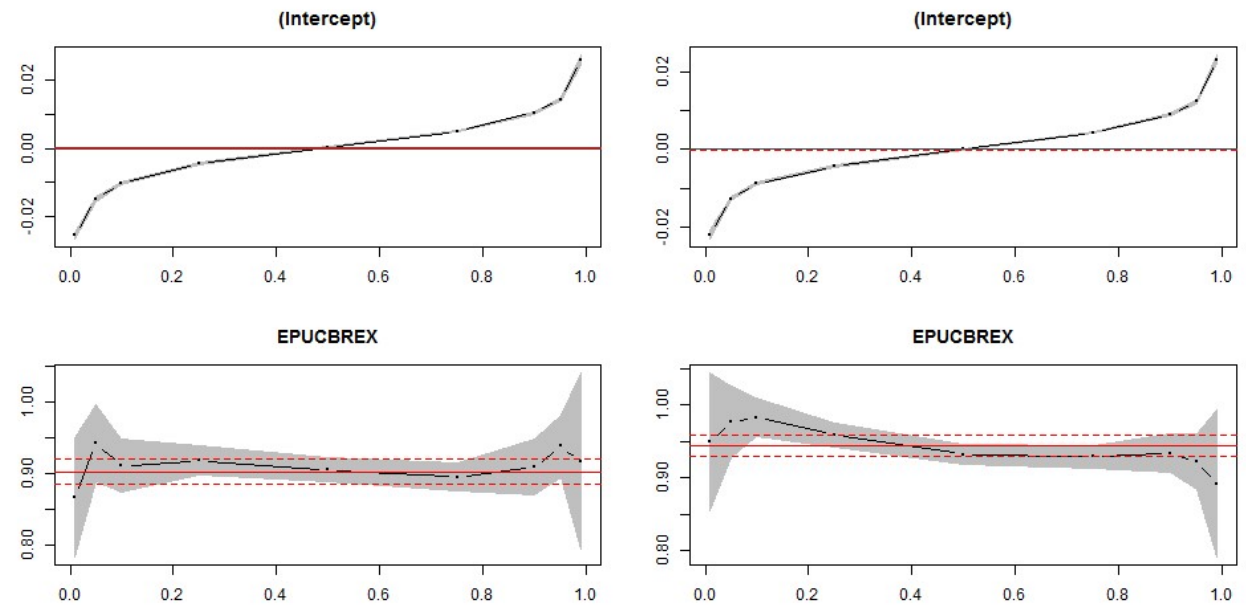

Source: Author's illustrations

Figure 2 Quantile regression estimates of the regression parameters for IRELAND, IBEX
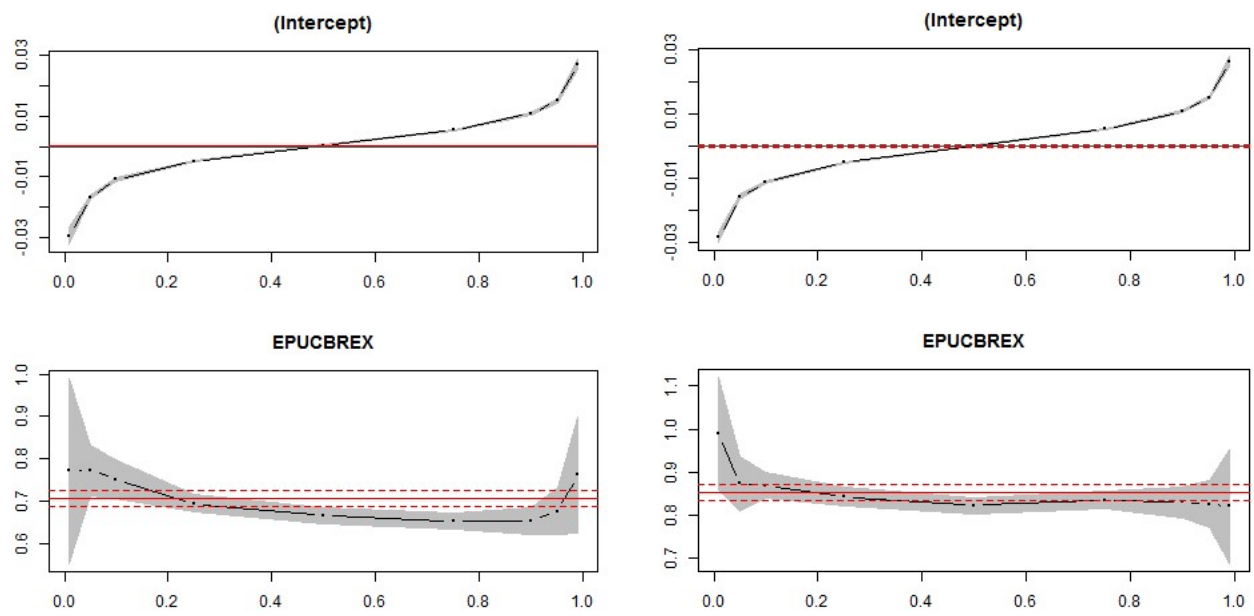

Source: Author's illustrations 
Figure 3 Quantile regression estimates of the regression parameters for WIG20, XU100
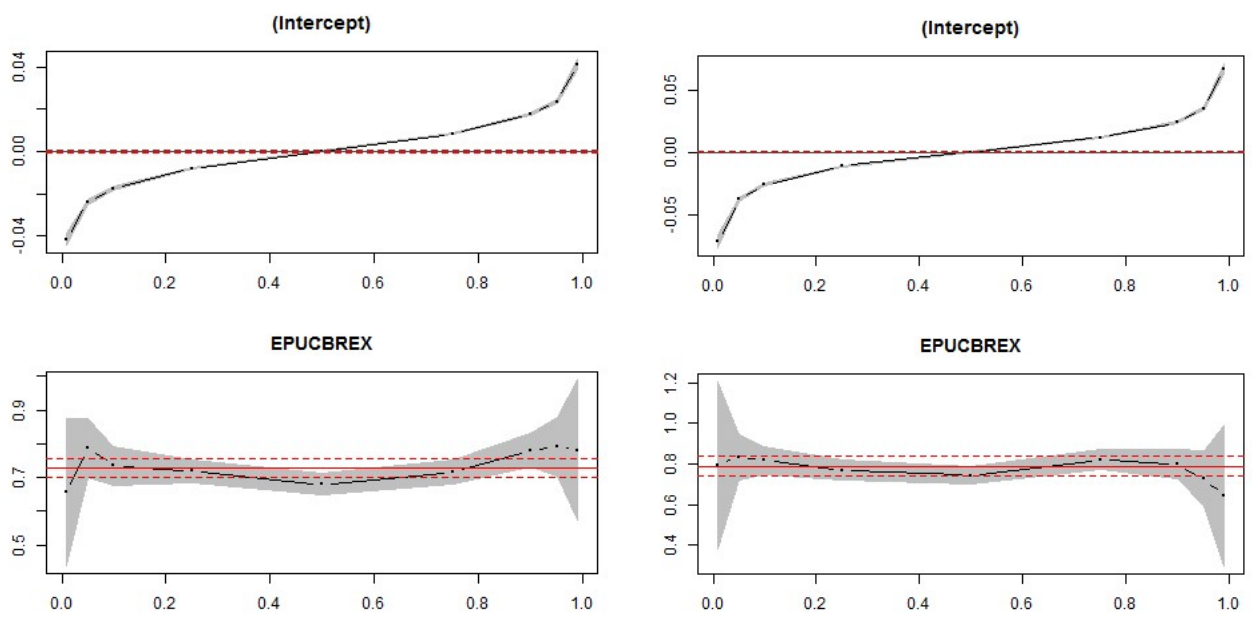

Source: Author's illustrations

Figure 4 Comparison of the Quantile regression estimates

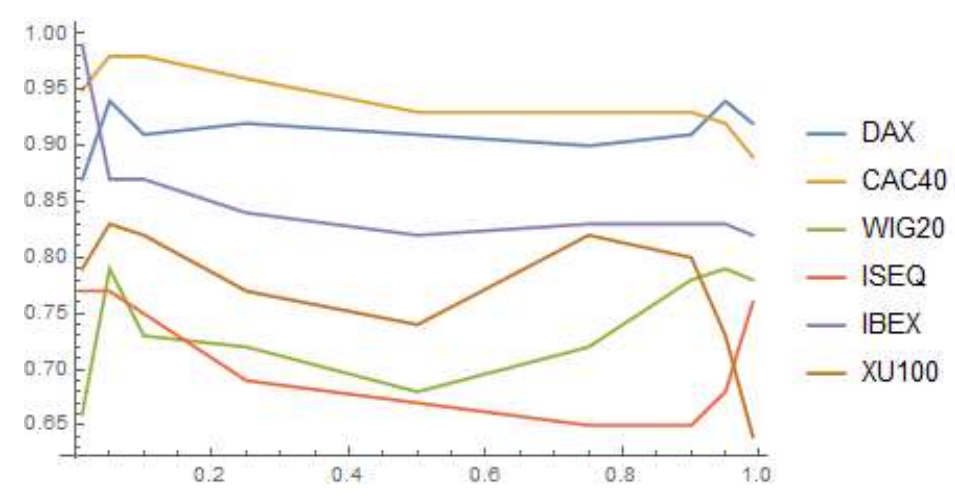

Source: Author's illustrations

Among the bull markets, Brexit had the greatest influence on German, French, Spanish, Polish, and Irish markets and the lowest on the Turkish stock market. Under standard business conditions expressed by the median, the French, then German, Spanish, Turkish, Polish, and finally Irish stock markets were the most affected.

Table 2 shows the effect of Brexit vote one day after voting. All results are discussed at $5 \%$ confidence level. We have estimated the quantile regression coefficients of the equation (5). The effect of the Brexit uncertainty is similar to the one described in Table 1. Now we describe the effect of Brexit vote one day after voting. Brexit vote had a slightly negative significant impact on German market, from the lower quartile to upper quartile, it means the result of the voting significantly affected 
normal market conditions mainly. For France, Brexit voting caused decrease in the CAC40 returns, too. This dependence structure is significant negative from median values to $90 \%$ quantile. The Polish and Spanish markets were not influenced by the Brexit vote. The dependence structure between Irish market and post vote period was significant positive only for lower quartile and median. Brexit vote had a negative significant impact on the Turkish market from $10 \%$ quantile to $75 \%$ quantile.

Comparing the period before the Brexit vote and one day after the vote, in the case of the German, French and Turkish markets among normal markets, their dependence changed to negative dependence. These dependences remain significant on the second and third day after the vote. Irish market remains independent of the Brexit vote after the second day. Similarly, our analysis shows that Polish and Spanish markets are independent of the Brexit vote.

Figure 5 shows an estimate of the quantitative regression coefficients $\beta(q)$ and $\gamma(q)$ one, two and three days after the vote. While the estimated coefficients $\beta(q)$ for individual markets before voting are more or less comparable, after the vote, the markets responded more strongly on the second and the third days, respectively. The Brexit vote significantly negatively hit the French market from $10 \%$ to $90 \%$ percentile on the second and the third day after the vote. The Polish market was also negatively affected by the vote, but this influence was not statistically significant. The impact of the vote on the Irish and Spanish markets was not statistically significant.

Table 2 Quantile regression estimates of the coefficients

\begin{tabular}{|c|c|c|c|c|c|c|c|c|c|c|}
\hline & & 0.01 & 0.05 & 0.10 & 0.25 & 0.50 & 0.75 & 0.90 & 0.95 & 0.99 \\
\hline \multirow{8}{*}{ DAX } & $\alpha(q)$ & -0.03 & -0.02 & -0.01 & 0.00 & 0.00 & 0.00 & 0.01 & 0.01 & 0.03 \\
\hline & t-stat & -43.54 & -38.09 & -32.21 & -31.51 & 2.38 & 33.15 & 33.39 & 41.32 & 28.36 \\
\hline & $\beta(q)$ & 0.86 & 0.94 & 0.93 & 0.93 & 0.91 & 0.90 & 0.91 & 0.94 & 0.92 \\
\hline & $t$-stat & 19.15 & 31.01 & 37.14 & 83.73 & 91.17 & 78.20 & 37.96 & 35.18 & 13.10 \\
\hline & $\gamma(q)$ & 0.01 & 0.01 & 0.00 & 0.00 & 0.00 & 0.00 & 0.00 & 0.00 & -0.01 \\
\hline & t-stat & 4.42 & 2.54 & 2.30 & 2.15 & 0.67 & -1.39 & -1.20 & -1.72 & -1.77 \\
\hline & $\theta(q)$ & -0.16 & -0.26 & -0.21 & -0.16 & -0.19 & -0.17 & -0.19 & -0.17 & -0.54 \\
\hline & $t$-stat & -0.62 & -1.49 & -1.47 & -2.61 & -3.28 & -2.55 & -1.37 & -1.13 & -1.35 \\
\hline \multirow{8}{*}{ CAC40 } & $\alpha(q)$ & -0.02 & -0.01 & -0.01 & 0.00 & 0.00 & 0.00 & 0.01 & 0.01 & 0.02 \\
\hline & $t$-stat & -38.33 & -35.14 & -42.74 & -31.05 & 0.93 & 32.73 & 42.66 & 37.10 & 25.35 \\
\hline & $\beta(q)$ & 0.95 & 0.98 & 0.99 & 0.96 & 0.94 & 0.93 & 0.94 & 0.94 & 0.88 \\
\hline & $t$-stat & 21.49 & 35.42 & 61.46 & 89.86 & 106.85 & 91.79 & 57.69 & 36.16 & 13.04 \\
\hline & $\gamma(q)$ & 0.01 & 0.01 & 0.00 & 0.00 & 0.00 & 0.00 & 0.00 & 0.00 & -0.01 \\
\hline & t-stat & 3.33 & 3.28 & 3.27 & 1.91 & 0.23 & -1.09 & -1.23 & -2.10 & -2.19 \\
\hline & $\theta(q)$ & -0.14 & -0.12 & -0.11 & -0.10 & -0.15 & -0.17 & -0.24 & -0.22 & -0.11 \\
\hline & $t$-stat & -0.56 & -0.73 & -1.19 & -1.56 & -2.95 & -2.96 & -2.57 & -1.51 & -0.28 \\
\hline
\end{tabular}




\begin{tabular}{|c|c|c|c|c|c|c|c|c|c|c|}
\hline & & 0.01 & 0.05 & 0.10 & 0.25 & 0.50 & 0.75 & 0.90 & 0.95 & 0.99 \\
\hline \multirow{8}{*}{ WIG20 } & $\alpha(q)$ & -0.04 & -0.02 & -0.02 & -0.01 & 0.00 & 0.01 & 0.02 & 0.02 & 0.04 \\
\hline & $t$-stat & -32.70 & -35.38 & -39.31 & -29.93 & 0.89 & 31.05 & 43.06 & 34.93 & 24.58 \\
\hline & $\beta(q)$ & 0.67 & 0.78 & 0.74 & 0.73 & 0.69 & 0.73 & 0.79 & 0.81 & 0.78 \\
\hline & t-stat & 6.70 & 14.90 & 21.67 & 35.04 & 36.15 & 34.67 & 25.12 & 15.60 & 6.11 \\
\hline & $\gamma(q)$ & 0.02 & 0.01 & 0.01 & 0.00 & 0.00 & 0.00 & 0.00 & -0.01 & -0.01 \\
\hline & $t$-stat & 3.54 & 2.58 & 2.54 & 1.96 & -0.37 & -1.22 & -2.29 & -1.60 & -1.08 \\
\hline & $\theta(q)$ & -0.13 & -0.21 & -0.13 & -0.22 & -0.07 & -0.14 & -0.25 & -0.17 & -0.36 \\
\hline & $t$-stat & -0.22 & -0.70 & -0.67 & -1.86 & -0.62 & -1.17 & -1.38 & -0.58 & -0.49 \\
\hline \multirow{8}{*}{ ISEQ } & $\alpha(q)$ & -0.03 & -0.02 & -0.01 & 0.00 & 0.00 & 0.01 & 0.01 & 0.02 & 0.03 \\
\hline & $t$-stat & -17.61 & -35.89 & -30.11 & -31.01 & 2.48 & 34.22 & 43.61 & 32.42 & 32.76 \\
\hline & $\beta(q)$ & 0.76 & 0.76 & 0.73 & 0.69 & 0.66 & 0.65 & 0.66 & 0.67 & 0.76 \\
\hline & $t$-stat & 5.93 & 21.23 & 26.01 & 56.21 & 59.10 & 53.57 & 34.09 & 18.70 & 12.00 \\
\hline & $\gamma(q)$ & 0.00 & 0.00 & 0.00 & 0.00 & 0.00 & 0.00 & 0.00 & 0.00 & -0.01 \\
\hline & $t$-stat & -0.11 & 1.13 & 1.42 & 1.19 & 0.76 & -0.29 & -2.26 & -1.72 & -2.99 \\
\hline & $\theta(q)$ & 0.59 & 0.38 & 0.09 & 0.17 & 0.20 & 0.11 & 0.13 & -0.04 & -0.04 \\
\hline & $t$-stat & 0.81 & 1.87 & 0.55 & 2.44 & 3.08 & 1.64 & 1.15 & -0.20 & -0.10 \\
\hline \multirow{8}{*}{ IBEX } & $\alpha(q)$ & -0.03 & -0.02 & -0.01 & -0.01 & 0.00 & 0.01 & 0.01 & 0.02 & 0.03 \\
\hline & $t$-stat & -25.19 & -29.89 & -46.93 & -30.88 & 0.88 & 32.99 & 37.10 & 34.51 & 30.49 \\
\hline & $\beta(q)$ & 0.92 & 0.87 & 0.86 & 0.84 & 0.82 & 0.84 & 0.83 & 0.85 & 0.87 \\
\hline & $t$-stat & 10.77 & 20.84 & 46.68 & 65.86 & 73.44 & 66.97 & 36.76 & 24.98 & 12.94 \\
\hline & $\gamma(q)$ & 0.00 & 0.00 & 0.00 & 0.00 & 0.00 & 0.00 & 0.00 & 0.00 & -0.01 \\
\hline & $t$-stat & 0.43 & 1.33 & 1.88 & 1.59 & 0.68 & -0.22 & -0.71 & -1.07 & -1.91 \\
\hline & $\theta(q)$ & 0.27 & 0.25 & 0.14 & 0.06 & 0.06 & -0.04 & -0.12 & -0.27 & -0.21 \\
\hline & $t$-stat & 0.55 & 1.04 & 1.28 & 0.85 & 0.95 & -0.61 & -0.91 & -1.42 & -0.54 \\
\hline \multirow{8}{*}{ XU100 } & $\alpha(q)$ & -0.08 & -0.04 & -0.03 & -0.01 & 0.00 & 0.01 & 0.02 & 0.04 & 0.07 \\
\hline & t-stat & -19.70 & -39.88 & -49.31 & -28.43 & 1.41 & 31.46 & 44.85 & 31.22 & 27.84 \\
\hline & $\beta(q)$ & 0.78 & 0.84 & 0.82 & 0.78 & 0.76 & 0.86 & 0.81 & 0.77 & 0.62 \\
\hline & t-stat & 2.62 & 11.48 & 20.04 & 26.22 & 30.76 & 29.00 & 19.29 & 8.85 & 3.38 \\
\hline & $\gamma(q)$ & 0.02 & 0.01 & 0.01 & 0.00 & 0.00 & 0.00 & -0.01 & -0.01 & -0.01 \\
\hline & $t$-stat & 0.85 & 2.37 & 3.25 & 0.82 & -0.74 & -2.03 & -2.41 & -2.03 & -0.83 \\
\hline & $\theta(q)$ & -0.94 & -0.49 & -0.55 & -0.42 & -0.41 & -0.38 & -0.39 & -0.45 & -1.28 \\
\hline & $t$-stat & -0.55 & -1.18 & -2.36 & -2.48 & -2.89 & -2.27 & -1.63 & -0.91 & -1.22 \\
\hline
\end{tabular}

Source: Author's calculations based on data from Bloomberg

The Brexit vote has had the most striking negative influence on the Turkish market during the first three days from $10 \%$ to $90 \%$ quantiles. 
Figure 5 Changes of the quantile regression estimates of the regression parameters (part I)
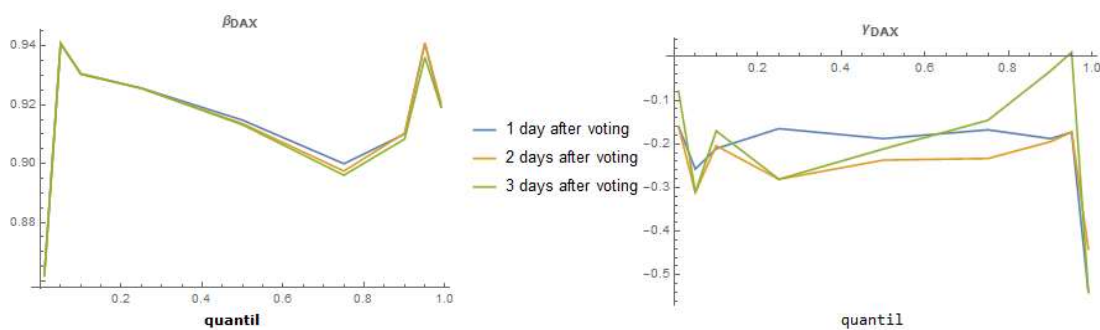

-1 day after voting

- 2 days after voting

- 3 days after voting
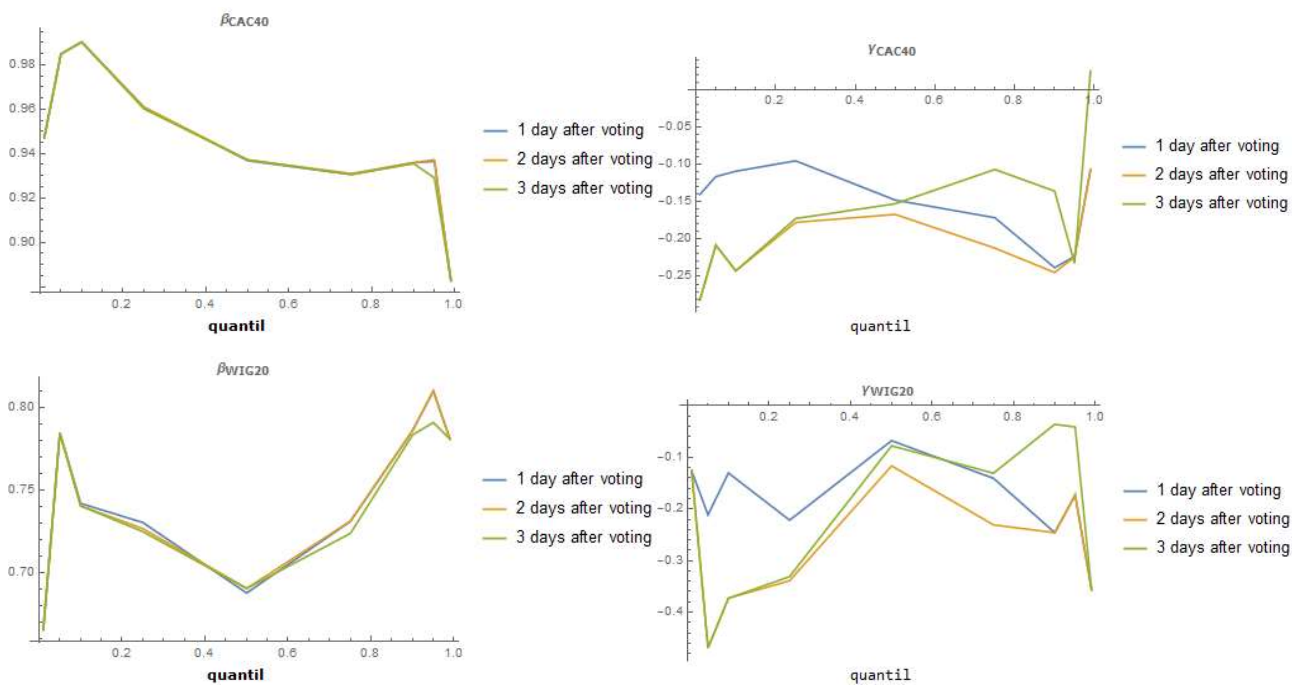

-1 day after voting

- 2 days after voting

3 days after voting
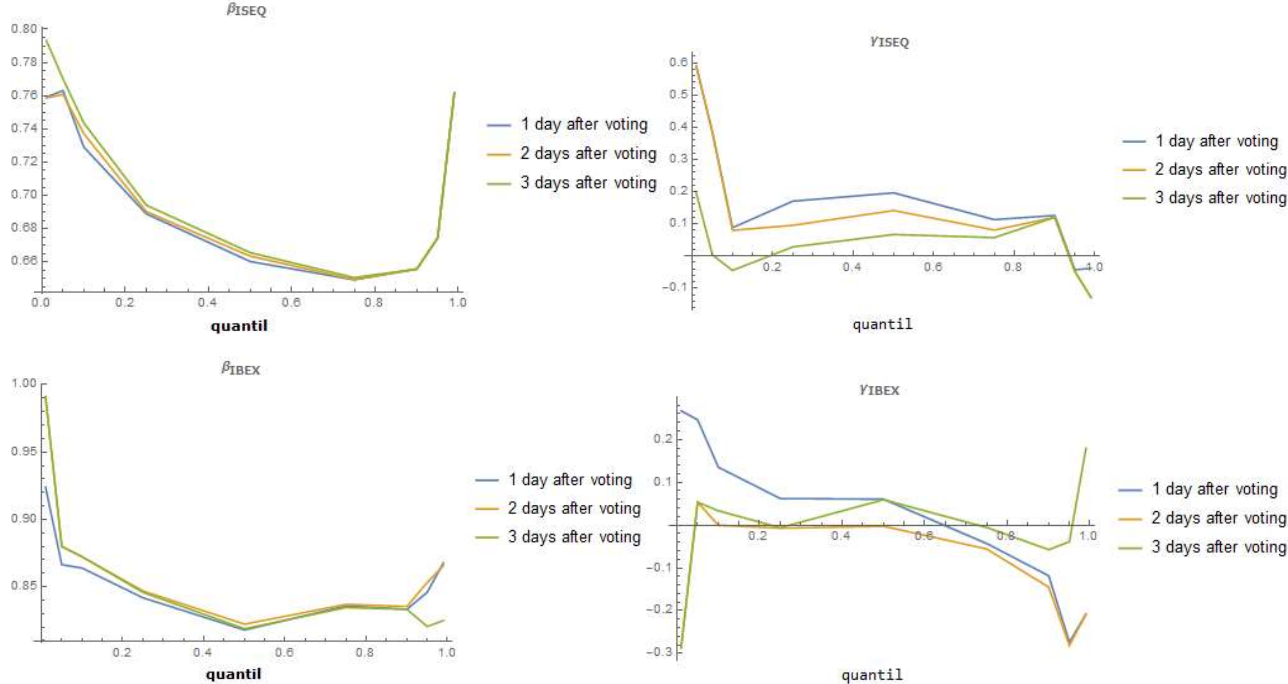
Figure 5 Changes of the quantile regression estimates of the regression parameters (part II)

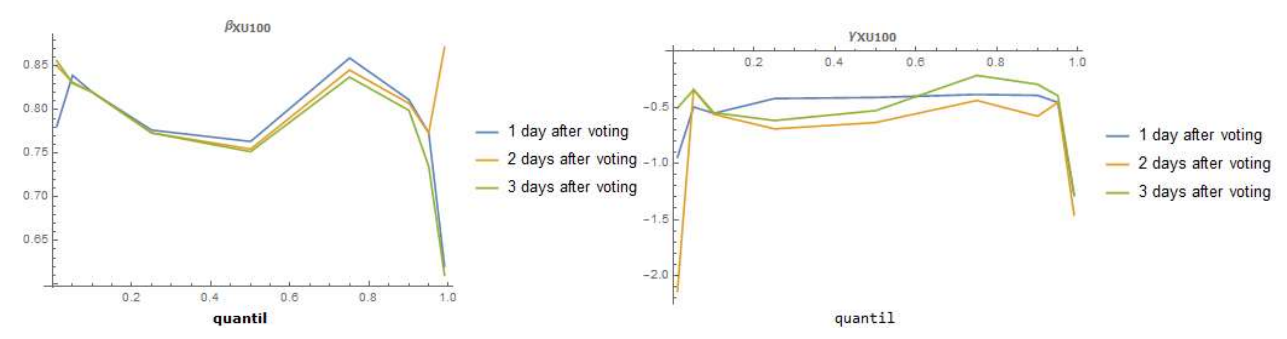

Source: Author's illustrations

\section{Conclusions}

Our paper contributes to the existing literature by assessing the impact of the Brexit uncertainty and Brexit vote on selected developed and emerging European stock markets across different quantiles of the return distributions. Our empirical evidence for the daily data from January, 7, 2000 to February, 3, 2017 indicates positive significant dependence between the selected EU stock markets and Brexit uncertainty. The positive influence of the Brexit on stock market means that comovement between selected country stock market indices and uncertainty caused by Brexit has increased. However, the contagion effect, i.e. an increased comovement from lower quantiles to the upper quantiles, has not been confirmed. We have found that Brexit uncertainty has had an asymmetric influence on individual stock markets. It influenced bear markets (when stock market prices fall) more than bull markets (when stock market prices grow). This result indicates that investors behave differently in extreme conditions. Our findings are similar to Raddant (2016) findings, who observed similar effects of the Brexit vote in Germany, France, Spain and Italy, but our results have provided closer look on this dependence structure.

Quantile regression results presented in this paper exhibit a detailed insight into the dependence structure to better understand financial market behavior and the linkage to Brexit. We have found that one, two or three days after the vote the dependence structure changed significantly mainly in normal market conditions for French, Turkish and German markets, while Polish and Spanish markets were not significantly influenced. The Irish market was significantly affected only the first day after the Brexit vote.

Analysing the Brexit strives to be helpful for international investors, portfolio risk managers, traders, as well as policymakers in order to avoid the downside risk in their investments. Uncertainty about future agreements between the UK and the EU and changes in the future EU financial infrastructure still remains, and the two- 
year period when the process of leaving the EU is finalized can therefore bring some interesting developments.

\section{References}

Alexander, C. (2008). Market Risk Analysis. Chichester: John Wiley \& Soons.

Aymen, B.R. and Mongi, A. (2016). Financial Market Interdependencies: A Quantile Regression Analysis of Volatility Spillover. Research in International Business and Finance, 36, pp. 140-157.

Bae, K.H., Karolyi, G.A. and Stulz, R.M. (2003). A New Approach to Measuring Financial Contagion. Review of Financial Studies, 16(3), pp. 717-763.

Baker, S.R., Bloomb, N. and Davis, S.J. (2015). Measuring Economic Policy Uncertainty. CEP Discussion Paper No 1379. Centre for Economic Performance. Available at: http://eprints.Ise.ac.uk/64986/1/dp1379.pdf.

Baur, D.G. (2013). The Structure and Degree of Dependence: A Quantile Regression Approach. Journal of Banking \& Finance, 37(3), pp. 786-798.

Embrechts, P., McNeil, A. and Straumann, D. (2002). Correlation and Dependence in Risk Management: Properties and Pitfalls. In: Dempster, M.A.H. (ed.): Risk Management: Value at Risk and Beyond. Cambridge: Cambridge University Press.

Embrechts, P., Lindskog, F. and McNeil, A. (2003). Modelling Dependence with Copulas and Applications to Risk Management. In: Rachev, S. (ed.): Handbook of Heavy Tailed Distributions in Finance. Amsterdam: Elsevier.

Hu, L. (2006). Dependence Patterns Across Financial Markets: A Mixed Copula Approach. Applied Financial Economics, 16(10), pp. 717-729.

Jackowicz, K. Kozłowski, Ł. and Podgórski, B. (2017). The Distant Echo of Brexit: Did Exporters Suffer the Most? Finance Research Letters, 21, pp. 132-139.

Koenker, R. and Bassett, G. (1978). Regression Quantiles. Econometrica, 46(1), pp. 33-50.

Mensi, W., Hammoudeh, S., Reboredo, J.C. and Nguyen, D.K. (2014). Do Global Factors Impact BRICS Stock Markets? A Quantile Regression Approach. Emerging Markets Review, 19 pp. 1-17.

Plakandaras, V., Gupta, R. and Wohar, M.E. (2017). The Depreciation of the Pound Post-Brexit: Could it Have Been Predicted? Finance Research Letters, 21, pp. 206213.

Raddant, M. (2016). The Response of European Stock Markets to the Brexit. Kiel Policy Brief, No. 100. IFW Kiel Institute for the world economy. Available at: https://www.ifw-kiel.de/wirtschaftspolitik/zentrum-wirtschaftspolitik/kiel-policybrief/kpb-2016/kpb_100.pdf. 
Ringe, W.G. (2017). The Irrelevance of Brexit for the European Financial Market. Oxford Legal Studies Research Paper No 10/2017. Available at SSRN: https://ssrn.com/abstract $=2902715$.

Schiereck, D., Kiesel, F. and Kolaric, S. (2016). Brexit: (Not) another Lehman Moment for Banks? Finance Research Letters, 19, pp. 291-297.

Sita, B.B. (2017). Volatility Patterns of the Constituents of FTSE100 in the Aftermath of the U.K. Brexit Referendum. Finance Research Letters, 23, pp. 137146. 